\title{
Forest Resources Assessments: Mensuration, Inventory and Planning
}

\author{
Iciar Alberdi (10)
}

Citation: Alberdi, I. Forest Resources Assessments: Mensuration, Inventory and Planning. Forests 2021, 12, 296. https://doi.org/10.3390/f12030296

Received: 1 March 2021

Accepted: 3 March 2021

Published: 4 March 2021

Publisher's Note: MDPI stays neutral with regard to jurisdictional claims in published maps and institutional affiliations.

Copyright: (C) 2021 by the author. Licensee MDPI, Basel, Switzerland. This article is an open access article distributed under the terms and conditions of the Creative Commons Attribution (CC BY) license (https:// creativecommons.org/licenses/by/ $4.0 /)$.
Dpto. Selvicultura y Gestión de los Sistemas Forestales, Instituto Nacional de Investigación y Tecnología Agraria y Alimentaria (INIA)-Centro de Investigación Forestal (CIFOR), Ctra. La Coruña km. 7.5, 28040 Madrid, Spain; alberdi.iciar@inia.es

There is much demand for forest information at the regional, national, and international level, covering aspects as varied as growing stock, carbon pools, and non-wood forest products, as well as information on forest biodiversity, risks, and disturbances, or social indicators. To objectively address these demands, intensive monitoring of the status of forests is required. Additionally, in this era of information, there are many ground- and remote-sensing-sourced forest databases with different time and spatial scales that could be combined to produce more complete estimates of forest status and trends. These challenging integration techniques can help to improve planning and management decisions.

National forest inventories (NFIs) provide one of the main sources of large-scale forest information. Kangas et al. [1] provide insights into the potential of national forest inventories (NFIs) but also highlight the challenges and the need to acknowledge measurement and model errors in addition to sampling errors. Although design-unbiased results at regional and national scales can be obtained, upscaling and downscaling the information requires a model-based approach using possibly biased estimators. The application of model-assisted estimators using auxiliary information has the potential to increase the precision, although the consistency of these estimators and corresponding variance estimators should be analyzed. Additionally, McConville et al. [2] present a tutorial on several parametric, model-assisted estimators to provide guidance for their use in forest inventory applications. Both studies identify the need to acknowledge the possibility of bias and its implications for all data used, also for policy making. In fact, the diverse information contained in NFIs provides a vital tool for large-scale forest planning and management. Kuliesis et al. [3] propose that the estimation and control of the gross annual increment and its components (growing stock volume change, volume of felled and dead trees) be considered in sustainable forest management as a means to ensure that wood use is rationalized in large areas. NFI data are also frequently used for forecasting purposes. A study by Adame et al. [4] focuses for the first time on forecasting the variation in forest carbon stocks and living biomass in Mediterranean forests due to forest management practices and wildfires. The results highlight the potential benefit of forest management for carbon storage. However, large-scale analyses may also have shortcomings, as reported by Marin et al. [5] in a study of diameter and basal area growth variation at national scale using increment cores acquired in the NFI for three prominent species in Romania. This study revealed that countrywide growth models can incorporate too much variability to be considered operationally feasible.

To obtain consistent, reliable results for forest ecosystems at international level, it is vital that the data are standardized or harmonized in order to upscale the information. Nunes et al. [6] develop a homogeneous characterization of the forests of the Iberian Peninsula using data from the NFIs of Portugal and Spain to classify and identify forest types. This harmonized information allows cross-border analysis of various aspects, such as hazards and wildfires, as well as facilitating management and conservation of forest biodiversity. 
Information on canopy cover (considered a multipurpose ecological indicator) can be derived from field measurements, statistical models or remote sensing. Given the importance of the techniques employed to analyze canopy cover, several studies have focused on this issue. Zhou et al. [7] compare the ability of two high spatial resolution sensors (SPOT6 and Gaofen-2) using three different ensemble learning models to estimate canopy cover in subtropical forest. Li et al. [8] develop a simple method to accurately map tea plantations based on their unique phenological characteristics, observed from Vegetation and Environment monitoring on a New Micro-Satellite (VEN $\mu S$ ) high-spatiotemporalresolution microsatellite. The accuracy of this method was above $90 \%$, although slightly lower accuracy was achieved when using Sentinel-2 images.

There has been a shift in the aims of forest policy and management from wood production to sustainable ecosystem management. Consequently, we are entering an innovative period in which multi-objective and multi-source forest inventories will be needed not only to assess forest resources but also to enhance the multifunctional role of forests. Hence, the estimates of traditional key variables, such as diameter and height, are currently being improved, while other variables associated with aspects such as biodiversity or disturbances are also being considered. Zea-Camaño et al. [9] improve the modelling of height-diameter relationships of tree species with high growth variation (in this case the balsa tree) by using robust regressions with iteratively reweighted least squares for datasets stratified by site index and age classes. Moe et al. [10] compare tree height information derived from field surveys, light detection and ranging (LiDAR), and aerial photographs derived from unmanned aerial vehicle unmanned aerial vehicle (UAV-DAP) for high-value timber broadleaved species. UAV-DAP data showed comparable accuracy to LiDAR and field survey data. Akpo et al. [11] evaluate the differences in tree metrics using structure-from-motion multi-view stereo photogrammetry. They found that the accuracy of photogrammetric estimations of individual tree attributes is species dependent and that the position of the camera in relation to the subject substantially influences the degree of uncertainty of the measurements. With the aim of streamlining the process of course wood debris (CWD) measurement, Lopes et al. [12] present a novel volume mapping strategy to estimate the volume of both visible and occluded CWD in a study area located in the boreal forest of Alberta, Canada. This strategy involves using optical imagery and an infracanopy vegetation-index layer derived from multispectral aerial LiDAR. Starova et al. [13] analyze the structure of northern Siberian Spruce and Scots Pine Forests at different stages of post-fire succession. These authors report that the stand structure and regeneration activity of the two species differ substantially in the first half of succession. Xiao et al. [14] suggest that the carbon and nitrogen stock capacity of the forest ecosystem can vary greatly among different forest types with the same tree layer and different understory vegetation, highlighting the need to consider the effects of the understory.

This Special Issue comprises a selection of papers reporting recent advances in forest resource assessment. Forest inventories of different scales and regions along with different remote sensing techniques have been used to further our knowledge in this vital area for forest management, planning and policy. Two relevant, practical reviews [1,2] are also contained in this Issue which highlight the importance of considering different methods depending on the challenge involved and scale of the information required.

I would like to thank the authors and the reviewers of the papers published in this Special Issue for their valuable contributions as well as the members of the editorial board and staff of the journal for their kind support in its preparation.

Funding: I.A. was supported by the Agreement EG12-0073 between the Ministry of Ecological Transition and the National Institute for Agricultural and Food Research and Technology (INIA).

Conflicts of Interest: The author declares no conflict of interest. 


\section{References}

1. Kangas, A.; Räty, M.; Korhonen, K.; Vauhkonen, J.; Packalen, T. Catering Information Needs from Global to Local Scales-Potential and Challenges with National Forest Inventories. Forests 2019, 10, 800. [CrossRef]

2. McConville, K.; Moisen, G.; Frescino, T. A Tutorial on Model-Assisted Estimation with Application to Forest Inventory. Forests 2020, 11, 244. [CrossRef]

3. Kuliešis, A.; Kasperavičius, A.; Kulbokas, G.; Kuliešis, A.; Pivoriūnas, A.; Aleinikovas, M.; Šilinskas, B.; Škèma, M.; Beniušienè, L. Using Continuous Forest Inventory Data for Control of Wood Production and Use in Large Areas: A Case Study in Lithuania. Forests 2020, 11, 1039. [CrossRef]

4. Adame, P.; Cañellas, I.; Moreno-Fernández, D.; Packalen, T.; Hernández, L.; Alberdi, I. Analyzing the Joint Effect of Forest Management and Wildfires on Living Biomass and Carbon Stocks in Spanish Forests. Forests 2020, 11, 1219. [CrossRef]

5. Marin, G.; Strimbu, V.; Abrudan, I.; Strimbu, B. Regional Variability of the Romanian Main Tree Species Growth Using National Forest Inventory Increment Cores. Forests 2020, 11, 409. [CrossRef]

6. Nunes, L.; Moreno, M.; Alberdi, I.; Álvarez-González, J.; Godinho-Ferreira, P.; Mazzoleni, S.; Castro Rego, F. Harmonized Classification of Forest Types in the Iberian Peninsula Based on National Forest Inventories. Forests 2020, 11, 1170. [CrossRef]

7. Zhou, J.; Dian, Y.; Wang, X.; Yao, C.; Jian, Y.; Li, Y.; Han, Z. Comparison of GF2 and SPOT6 Imagery on Canopy Cover Estimating in Northern Subtropics Forest in China. Forests 2020, 11, 407. [CrossRef]

8. Li, N.; Zhang, D.; Li, L.; Zhang, Y. Mapping the Spatial Distribution of Tea Plantations Using High-Spatiotemporal-Resolution Imagery in Northern Zhejiang, China. Forests 2019, 10, 856. [CrossRef]

9. Zea-Camaño, J.; Soto, J.; Arce, J.; Pelissari, A.; Behling, A.; Orso, G.; Guachambala, M.; Eisfeld, R. Improving the Modeling of the Height-Diameter Relationship of Tree Species with High Growth Variability: Robust Regression Analysis of Ochroma pyramidale (Balsa-Tree). Forests 2020, 11, 313. [CrossRef]

10. Moe, K.; Owari, T.; Furuya, N.; Hiroshima, T. Comparing Individual Tree Height Information Derived from Field Surveys, LiDAR and UAV-DAP for High-Value Timber Species in Northern Japan. Forests 2020, 11, 223. [CrossRef]

11. Akpo, H.; Atindogbé, G.; Obiakara, M.; Adjinanoukon, A.; Gbedolo, M.; Lejeune, P.; Fonton, N. Image Data Acquisition for Estimating Individual Trees Metrics: Closer Is Better. Forests 2020, 11, 121. [CrossRef]

12. Lopes Queiroz, G.; McDermid, G.; Linke, J.; Hopkinson, C.; Kariyeva, J. Estimating Coarse Woody Debris Volume Using Image Analysis and Multispectral LiDAR. Forests 2020, 11, 141. [CrossRef]

13. Stavrova, N.; Gorshkov, V.; Katjutin, P.; Bakkal, I. The Structure of Northern Siberian Spruce-Scots Pine Forests at Different Stages of Post-Fire Succession. Forests 2020, 11, 558. [CrossRef]

14. Xiao, R.; Man, X.; Duan, B. Carbon and Nitrogen Stocks in Three Types of Larix gmelinii Forests in Daxing'an Mountains, Northeast China. Forests 2020, 11, 305. [CrossRef] 